\title{
Bipolar Disorder and Research: Understanding What We Know, What We Don't Know, and Where the Future May Lead
}

\author{
By Jack M. Gorman, MD
}

Sometimes, trying to understand bipolar disorder seems harder than holding on to a handful of water drawn from a rapidly moving stream: No matter where you put your hand, you grasp nothing firm enough to make a definitive case.

How common is bipolar disorder?

If we restrict ourselves to bipolar I disorder, perhaps $1 \%$ of the population. This is hardly a satisfying answer, however, because that restriction is clearly invalid. There are so many forms of bipolar disorder ranging, for example, in cycle length and frequency, severity, and presence of psychosis, that the prevalence seems to range from rare to almost every patient with a psychiatric illness.

Is it genetic? Probably, but the genes are remarkably elusive. Is it treatable? Of course, but the field has gone from thinking about lithium, the gold standard by which all successful medical therapies could be compared with, to massive demoralization. Some now insist that lithium hardly ever works. In its place, an anticonvulsant is now the most frequently prescribed treatment for bipolar disorder, even though it has never been shown to be more effective or safer than lithium and is certainly more expensive. Other anticonvulsants crop up seemingly monthly, and clinicians prescribe them often, despite the fact that data for the usefulness of compounds like gabapentin and topiramate for bipolar disorder are clearly negative.

As someone who treats many bipolar patients, I can say that the news is not nearly as dismal as some would lead us to believe. Although a challenging condition to have or to treat, most patients with bipolar disorder, have positive responses to medical therapies. Included among those therapies must be psychotherapy com- bined with medication, as there is now abundant evidence that psychosocial interventions are important and effective in the total treatment package for patients with bipolar disorder.

I insist that bipolar illness is not really everywhere we look, although it is more common than we previously believed, it does occur in children and adolescents, and it can become a chronic illness. Nevertheless, the attempt to insist that every inattentive and irritable child or every depressed patient who once had a moment of serenity is really bipolar is nonsense.

These issues are among those that prompted me to ask my longtime friend David L. Dunner, MD, FACP, to guest edit this month's issue of CNS Spectrums. Dave may not like my bringing this up, but he was one of our favorite and most admired professors when I was a medical student, and when he left Columbia University in New York City not long thereafter for the University of Washington in Seattle, we were all sad to lose him. He is one of the pioneers in bipolar disorder research and clinical care, having played a major role in the development of lithium in the first place, and in many subsequent breakthroughs. Above all, I believe he is one of the few who consistently brings the weight of evidence to our understanding of this complex, often devastating, and always fascinating illness.

The articles in this issue helped me a great deal in sorting through the many conflicting ideas and beliefs that we have about bipolar disorder, and for that I am grateful to these authors and, most of all, to David Dunner. I hope all of our readers find this work informative and useful as well. CNS 